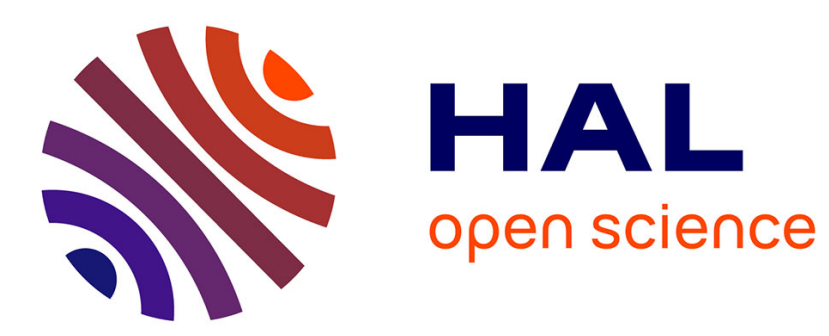

\title{
Temperature fields in a chip during high-speed orthogonal cutting-An experimental investigation
}

Guy Sutter, Nicolas Ranc

\section{To cite this version:}

Guy Sutter, Nicolas Ranc. Temperature fields in a chip during high-speed orthogonal cutting-An experimental investigation. International Journal of Machine Tools and Manufacture, 2007, 47 (10), pp.1507-1517. 10.1016/j.ijmachtools.2006.11.012 . hal-00171984

\section{HAL Id: hal-00171984 \\ https://hal.science/hal-00171984}

Submitted on 25 Feb 2018

HAL is a multi-disciplinary open access archive for the deposit and dissemination of scientific research documents, whether they are published or not. The documents may come from teaching and research institutions in France or abroad, or from public or private research centers.
L'archive ouverte pluridisciplinaire HAL, est destinée au dépôt et à la diffusion de documents scientifiques de niveau recherche, publiés ou non, émanant des établissements d'enseignement et de recherche français ou étrangers, des laboratoires publics ou privés. 


\title{
Temperature fields in a chip during high-speed orthogonal cutting-An experimental investigation
}

\author{
G. Sutter ${ }^{\mathrm{a}, *}$, N. Ranc $\mathrm{c}^{\mathrm{b}, \mathrm{c}}$ \\ ${ }^{a}$ L.P.M.M., U.M.R. C.N.R.S. No. 7554, I.S.G.M.P., Université de Metz, Ile du Saulcy, 57045 Metz Cedex 1, France \\ ${ }^{\mathrm{b}}$ L.E.E.E., E.A. 387, Université de Paris X - Nanterre, 1, Chemin Desvallières, 92410 Ville d'Avray, France \\ ${ }^{\mathrm{c}}$ L.M.S.P., U.M.R. C.N.R.S. No. 8106, ENSAM-ESEM, 151, Boulevard de l'Hôpital, 75013 Paris, France
}

\begin{abstract}
During the cutting process, the temperature field in the chip is measured by using the principle of pyrometry in the visible spectral range. The mechanical device developed to reproduce orthogonal cutting conditions and to reach very high cutting speed (up to $120 \mathrm{~m} / \mathrm{s}$ ) is used for a range of velocities from 10 to $70 \mathrm{~m} / \mathrm{s}$. The presented experimental results concern two materials chosen following the form of chip generated: a low carbon steel $(\mathrm{C} 15)$ and a low alloyed medium carbon steel (42CrMo4). The performances of the measurement set-up are completed by the possibility of recording real time photographs of the chip formation. These records make the analysis of temperature maps easier and allow specific parameters as the contact length at the tool-chip interface or the shear angle to be determined. The nonuniform heating in the chip is emphasized by the presence of a maximal temperature area. The temperature fields measured for a cutting speed around $20 \mathrm{~m} / \mathrm{s}$ present maximums of $870{ }^{\circ} \mathrm{C}$ for $42 \mathrm{CrMo} 4$ and $630{ }^{\circ} \mathrm{C}$ for $\mathrm{C} 15$ located near the tool-chip interface. The effects of cutting velocity on the maximum temperature value in the chip and the location of this heat zone are presented. This maximum increases with the cutting velocity contrary to its location which presents few variations. The experimental results are compared with an analytical approach.
\end{abstract}

Keywords: High-speed cutting; Visible pyrometry; Chip temperature distribution; Chip geometry; Thermal model

\section{Introduction}

The chip formation during metal cutting is a high shear strain process at very high strain rate involving very high hard contact condition between chip and tool. The work of plastic deformation as well as friction at the tool-chip interface is in a major part transformed into heat $[1,2]$. This heat contributes directly to increase the temperature of the chip and by conduction, of the tool. The rise of the temperature during the manufacturing determines thermomechanical behavior of the workpiece and so becomes one of important parameters in the definition of optimum conditions of cut (cutting speed, rake angle, depth of cut).

\footnotetext{
${ }^{*}$ Corresponding author. Tel.: +330387315367 ; fax: +330387315366 .

E-mail addresses: sutter@lpmm.univ-metz.fr (G. Sutter), nicolas.ranc@paris.ensam.fr (N. Ranc).
}

Indeed the thermal softening following this increase in the temperature can have as a consequence to make the cut easier by decrease of the cutting forces. However, it should be noted that the field of temperature in the chip is far from being uniform and is often characterized by zones of hightemperature gradients. Fig. 1 presents a chip of ductile material in orthogonal cutting process (copper at $V=21 \mathrm{~m} / \mathrm{s}$ ) and defines the different heat sources. This picture is obtained in real time with the numerical camera equipping the test bench.

In fact, during the cutting process the heating is located mainly in three zones, as shown in Fig. 1. The rise in temperature is initiated in the primary zone due to the high shear deformation. This local heating along a shear plane leads to a thermal softening of the workpiece material and tends to decrease the global cutting forces. Then, the heating initiated in the first zone increases during the contact with the tool. The heat generated in the secondary 


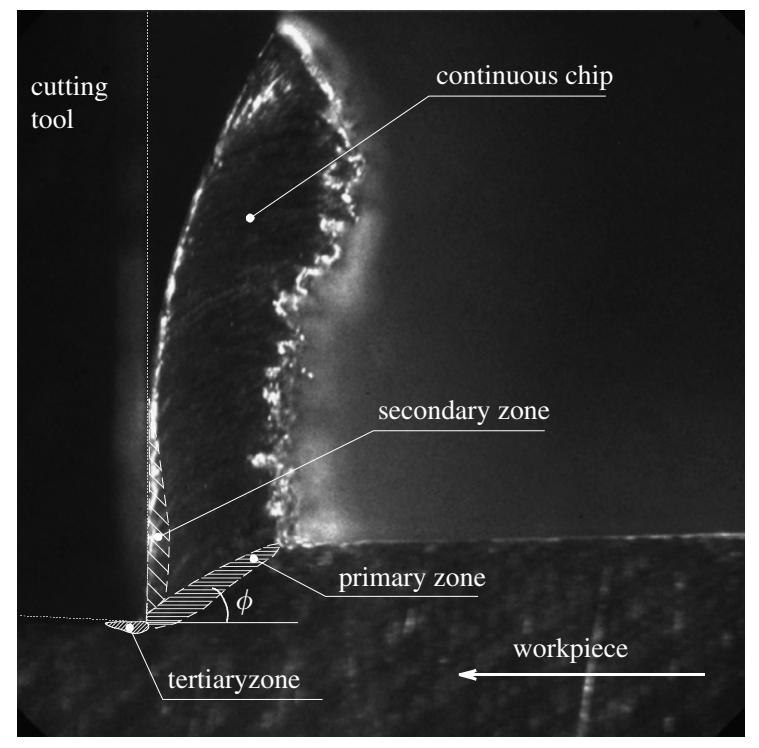

Fig. 1. Different zones of heat generation during orthogonal cutting process.

zone is consequent with the deformation of the chip along the rake face to which sliding friction is added. The temperature thus reached in the chip affects primarily the chip formation and by conduction the tool life and the tool wear. Under the tool tip, a tertiary zone is defined by elastic deformation and rubbing contact between the tool flank face and the machined surface. This heating controls also the tool life but mainly the quality, the tolerance and the integrity of the finished surface.

Temperature has a more harmful effect on the tool because it directly conditions the tool life by a fast evolution of wear [3]. A catastrophic process is then activated because the more the wear is significant the more tool-chip or tool-workpiece frictions are favorable to the rises in temperature. The existence of many coatings of tool making it possible to limit the diffusion of the temperature in the tool, well illustrates the importance of this phenomenon [4,5]. Finally, residual stresses can appear on the machined surface due to the heating generated near the cutting tool edge [6].

These observations explain and justify many works concerning the temperature measurement during the cutting process $[1,7,8]$. The knowledge of the temperature fields turns out to be an important parameter for the comprehension of the phenomena present during the cut. Various processes were developed to measure the temperature. They can be classified in two families: intrusive techniques (mainly with thermocouples) $[9,10]$ which provided selective measurements and non-intrusive techniques like pyrometry [11,12]. These last have the main advantages not to disturb the field of investigation and to have a very short response time (between a few microseconds and a few milliseconds). They also enable to measure temperature fields with a very good spatial resolution (in the order of a few microns).
The principle of pyrometry is based on the fact that the energy radiated by a surface depends on its temperature. Planck showed that a perfect emitter (black body) at the temperature $T$, emitted a maximum of energy at a given wavelength. This wavelength noted $\lambda_{\max }$ is given by the Wien displacement law:

$\lambda_{\max }=\frac{C_{2}}{5} \cdot \frac{1}{T}$,

with $C_{2}=14388 \mu \mathrm{m} \mathrm{K}$, the second radiation constant.

Fig. 2 represents the energy emitted by a unit of area in a unit solid angle (called intensity) according to the wavelength for various temperatures. This figure highlights the maximum of the radiated energy at a wavelength $\lambda_{\max }$. In the case of machining, the temperatures generated near the cutting area are between 200 and $1000^{\circ} \mathrm{C}$. The maximum of the radiated energy takes place, respectively, for the wavelengths of 6.1 and $2.3 \mu \mathrm{m}$ i.e. in the near infrared spectral range. This is why the majority of work which relates to the measurement of temperature fields in machining use the infra-red pyrometry technique. As Barrow [1] wrote in his review, the first report stating of this technique was reported in 1933 and the temperature field measurements by infra-red pyrometry during a machining process are currently found in a great number of papers $[7,8]$. Indeed, the technology of the IR cameras strongly improved these last decades. The reduction of the noise in the sensors allowed to develop increasingly sensitive pyrometers and the emergence of CCD matrix which made it possible to increase the number of sensors and thus to improve the spatial resolution. We can note that the infra-red pyrometry is used in two different experimental forms. The first application relates to the use of IR camera in order to measure temperature cartography. Generally the acquisition frequencies of this type of camera are too weak to make several cartographies during a machining process (from about $10 \mathrm{~Hz}$ to a maximum of a few hundreds of $\mathrm{Hz}$ ). The second application of the pyrometry relates to the use of a bar of detectors which allows on the contrary to measure the temporal evolution of the temperature at different locations with much higher frequencies (about $1 \mathrm{MHz}$ ) [13,14].

In pyrometry, the principal source of error on the temperature is related to the uncertainty on the surface emissivity. The emissivity is a thermo-optical property of the surface which depends on the composition and the structure of the surface material, the roughness and the temperature of the surface and the wavelength of the emitted radiation. This factor lies between 0 and 1 . An emissivity equal to 1 corresponds to the case of the black body. In machining, several authors underlined the need and the difficulty to know precisely the emissivity value in order to limit the error on the temperature determination $[15,16]$. In order to eliminate the measurement error, O'Sullivan and Cotterell [17] applied a coating of known emissivity on the workpiece and M'Saoubi [5], measures in static this emissivity by comparison between the power 


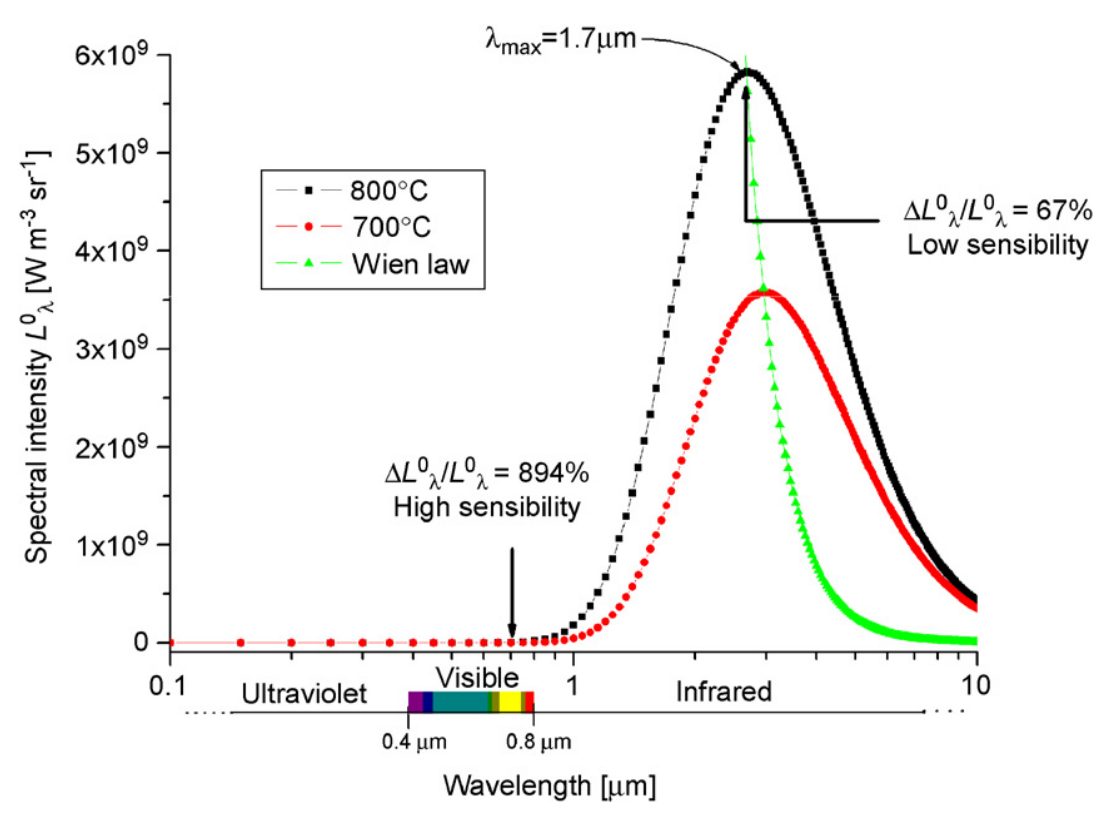

Fig. 2. Blackbody spectral intensity for temperatures of 700 and $800^{\circ} \mathrm{C}$.

emitted by the heated workpiece and the power emitted by a black body. However, as the chip is subjected to significant plastic deformations, the roughness of the chip surface, and thus its emissivity, strongly vary during a machining process. In the same way significant variations of the chip temperature modify its emissivity.

To solve this problem due to the uncertainty on emissivity during machining process, Muller [18] proposed a temperature measurement technique by two-color pyrometry. The principle is based on a double measure of the power emitted by the surface at two different wavelengths in the infra-red range $(1.7$ and $2 \mu \mathrm{m})$. By making the assumption of the gray body (emissivity independent of the wavelength), this technique allows the temperature and the emissivity of chip surface to be evaluated. The first disadvantage of this method comes from the fact that in reality the emissivity depends on the wavelength (surface is not like a gray body). The second disadvantage is that it is not easy to adapt this technique to field measurements.

To reduce to the maximum the error on the determination of the temperature, we proposed [19] a measurement technique by visible pyrometry (wavelength ranging between 0.4 and $0.8 \mu \mathrm{m}$ ). The choice of a wavelength smaller than that used in infra-red pyrometry enables to increase the sensitivity of the pyrometer to the temperature variations and thus to strongly limit the influence of the emissivity evolution during a high-speed machining test [16]. Fig. 2 also illustrates the increase in the sensitivity of the emitted energy according to the temperature variation in the case of a black body. Indeed, we can note that for a wavelength of $0.6 \mu \mathrm{m}$ (visible) and $2.7 \mu \mathrm{m}$ (infra-red) the relative variation of signal is, respectively, $894 \%$ and $67 \%$ for a temperature variation of the chip of $700-800{ }^{\circ} \mathrm{C}$. The sensitivity in the visible field is 13 times higher than in the infra-red range. As it can be underlined on Fig. 2, the major disadvantage of this technique is that for the short wavelengths, the chip emits low energy. To study fast phenomena, like high speed machining, it is necessary to have an extremely sensitive camera. Therefore we use an intensified CCD camera which is sensitive in the visible range.

In previous works [19], in order to study high speed machining of $42 \mathrm{CrMo} 4$ steel, an intensified camera Philips IP800 with an intensifier of second generation (sensitive in visible and the UV fields) was used and an interference filter centred on $0.8 \mu \mathrm{m}$ with a $0.01 \mu \mathrm{m}$ bandwidth. This device enabled to detect temperatures ranging between 650 and $850{ }^{\circ} \mathrm{C}$ with an aperture time of $64 \mu \mathrm{s}$. To extend investigation field to the less exothermic processes, the sensitivity of the device is increased by using a third generation camera with higher quantum efficiency in the visible range (AsGa photocathode) and a large wavelength range. This camera was used without interference filter and its spectral range extends between 0.4 and $0.8 \mu \mathrm{m}$. Minimal temperatures about 550 and $450{ }^{\circ} \mathrm{C}$ are detected by means of this new device, respectively, for aperture times of 64 and $600 \mu \mathrm{s}$. The larger dynamics of this camera (coding in 16 bits) enables to record a larger temperature range (the temperatures ranging between 550 and $950{ }^{\circ} \mathrm{C}$ for a aperture time $64 \mu \mathrm{s}$ ). Its matrix of 1024 by 1024 pixels ensures a very broad vision field and a better spatial resolution.

The large range of cutting speed investigated with this experimental set-up of cutting simulation is, up to now, not attained by industrial machines and is rarely investigated by research works. However, the range of the very high cutting speeds remains a need for the industrialists in order to increase their production outputs. These high cutting speeds need delicate measures and require a lot of time of perfecting to obtain reliable measurements. On the other 
hand, the performances due to the evolution of thermal measurement set-up, enable to investigate measurement during the manufacturing of a low carbon steel with weaker elastic limit (for example C15). Indeed, under these conditions the heat generation decrease and higher sensibility of the measurement set-up is required.

This paper presents at first the analysis of the temperature fields measured in the chip during formation. Rigorously orthogonal cutting conditions are realized on a specific ballistic device allowing high speeds to be reached. The thermal analysis of the chip formation is realized for two materials, a low steel carbon $(\mathrm{C} 15)$ and a low alloyed medium carbon steel $(42 \mathrm{CrMo} 4)$, selected mainly for the type of generated chips (continuous and segmented). In a second part, more systematic tests are made for $\mathrm{C} 15$ steel to follow the maximal values of temperature reached in the chip. These measurements are interpreted in the sights of results proposed by a simple modelling of the evolution of the temperature with the cutting speed. The friction coefficient as well as the cutting forces which are experimentally measured are nevertheless taken into account in this approach.

\section{Experimental set-up}

\subsection{Mechanical part}

To reproduce high-speed cutting process, an original experimental set-up was developed [20] and schematically presented Fig. 3. The workpiece is propelled by an air gun in a launch tube. Two symmetrical cutting tools are fixed at the entry of a second tube. The two tubes are coaxial. The workpiece is machined when it leaves the launch tube and just before to enter the second tube. A load sensor supporting the cutting tools measures the cutting forces during the process. An accurately adjustment between the projectile and the launch tube and fine adjustments result in a perfect positioning of the specimen and the cutting tools. The precision of the cutting is less than $0.015 \mathrm{~mm}$. The specimen geometry is meticulously measured before and after every test to determine the depths of cut for each side. On this test bench, it is possible to investigate a range of speeds from 15 to $120 \mathrm{~m} / \mathrm{s}$ by keeping the device very rigid and limiting parasite vibrations.

The intensified CCD camera which is used for thermal measurements and to visualize the chip geometry, is fixed directly over the cutting process (cf. Fig. 4). Micrometer screws ensure a position adjustment of the camera. The optical magnification is about $\times 3.3$ by means of reverse wide-angle lens. To limited parasite noises the cutting test are realized in a dark room or by using a black box. A perfect synchronization of the trigger mechanism with the photographic recording system is required. A set-up of photodiodes, time counters and light sources located at the end of the launch tube are used to measure the cutting speed and to give the synchronizing signal to the camera.

\subsection{Thermal part}

The temperature measurement device is similar to that presented by Ranc et al. [21]. It is composed of a Princeton Instruments intensified camera which is sensitive in the spectral band $0.4-0.8 \mu \mathrm{m}$. To focus the energy radiated by the surface of the chip, we use an objective with a $50 \mathrm{~mm}$ focal length. A space resolution of $3.6 \mu \mathrm{m}$ and an observation field of $3.7 \mathrm{~mm}$ by $3.7 \mathrm{~mm}$ are obtained with this optical device. The aperture time of the camera varies between 32 and $600 \mu$ s according to the tests. As the refresh time of the camera is higher than the machining duration, only one image will be taken during a test.

The pyrometer is calibrated on a Pyrox black body whose temperature can vary between 400 and $1600^{\circ} \mathrm{C}$. Three calibration curves of the pyrometer are given in Fig. 5, respectively, for aperture times of $64 \mu \mathrm{s}$ (gain of intensifier 200), $200 \mu$ s (gain of intensifier 255) and $600 \mu \mathrm{s}$ (gain of intensifier 255). If we suppose that the chip surface is like a black body, the calibration curves give the radiance temperature which is equal to the real temperature of the surface. As the surface of the chip does not behave like a black body, the real temperature of surface is different

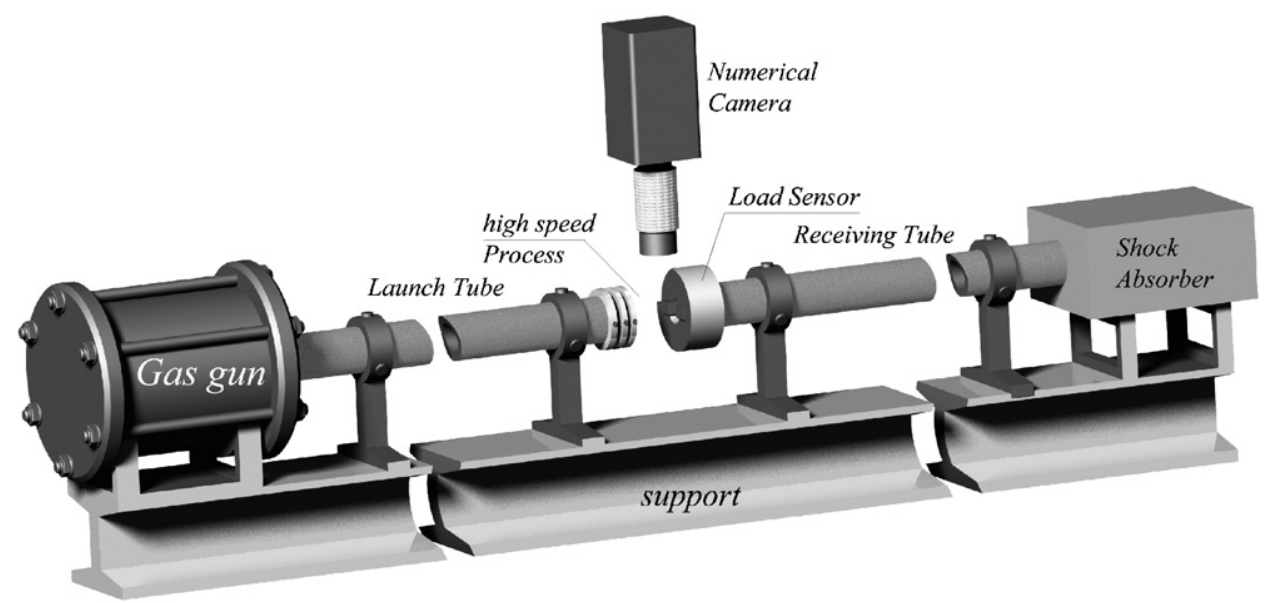

Fig. 3. Schematic description of the experimental set-up reproducing orthogonal cutting conditions allowing to reach high speeds. 


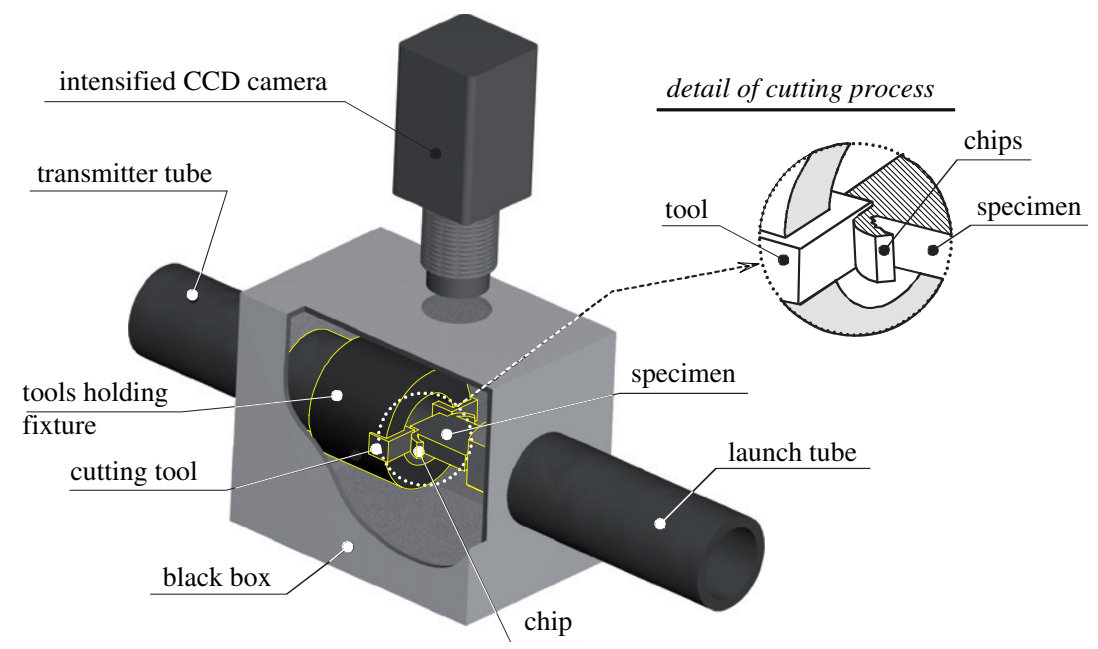

Fig. 4. Schematic representation of the thermal measurement system and detail of the recorded cutting zone.

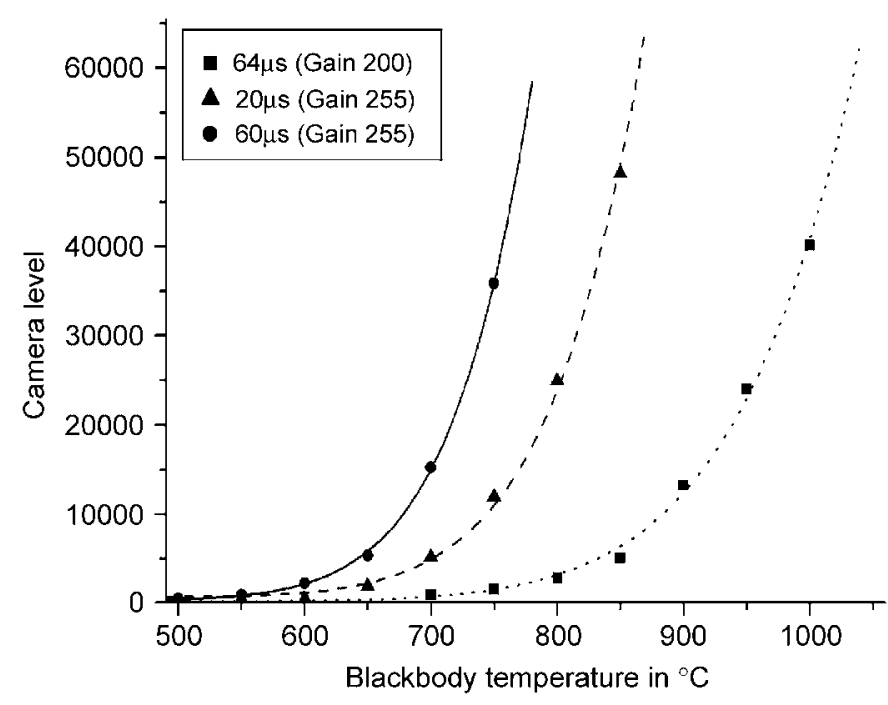

Fig. 5. Calibration curves according to the blackbody temperature.

from the radiance temperature. The curve of Fig. 6 presents the difference between the real temperature and the radiance temperature. This difference is given in the case of the visible pyrometry (a third generation intensified camera) and for example in the case of the near infra-red pyrometry (InSb photovoltaic detector). We can note that the use of the visible pyrometry limits the difference between the radiance temperature and the real temperature and thus the error on the estimation of the surface temperature. For a temperature of $800{ }^{\circ} \mathrm{C}$, in the case of the intensified camera and for an emissivity estimated at 0.4 from bibliographical data [22], the difference is $57^{\circ} \mathrm{C}$ (relative error of 5\%). By using an InSb detector in this spectral field the value of the emissivity is about 0.25 and the error would be $284^{\circ} \mathrm{C}$ (relative error $26 \%$ ). Later on, the radiance temperature will approximate the real temperature.

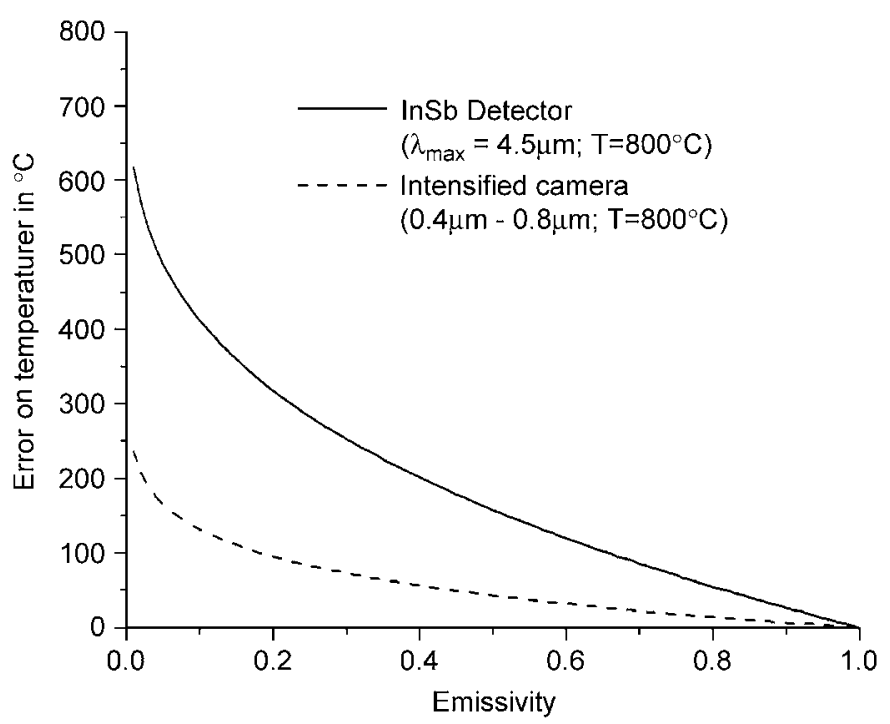

Fig. 6. Error on the temperature measurement according to emissivity at $800^{\circ} \mathrm{C}$ introduced by using, respectively, an InSb detector and an intensified camera.

\section{Results}

The chemical composition and the main mechanical characteristics of the two materials tested under orthogonal cutting conditions are indicated in Tables 1 and 2. The choice of these two materials is determined by the nature of chips obtained during the cutting. Their forms are, respectively, continuous for the $\mathrm{C} 15$ steel and segmented for the $42 \mathrm{CrMo} 4$ steel. The good accessibility of this set-up and its design further the photographic recordings of the chip morphology during the formation [23]. The pictures obtained so are placed side by side to the recording of temperature fields for close conditions (cf. Figs. 7a, 8a and 9a). For example, these recordings allow to quantify the contact length, $L_{\mathrm{C}}$, between the tool and the chip and to distinguish the shape of the chip. On Figs. 7a and 8a, the 
Table 1

Chemical composition of the low alloyed medium carbon steel $42 \mathrm{CrMo} 4$ and the low carbon steel $\mathrm{C} 15$

\begin{tabular}{|c|c|c|c|c|c|c|c|c|c|c|}
\hline Elements $\times 10^{-3}(\mathrm{wt} \%)$ & $\mathrm{C}$ & $\mathrm{Si}$ & $\mathrm{Mn}$ & $\mathrm{S}$ & $P$ & $\mathrm{Ni}$ & $\mathrm{Cr}$ & Mo & $\mathrm{Cu}$ & $\mathrm{Al}$ \\
\hline $\mathrm{C} 15$ & $140-200$ & - & $300-600$ & $\max 4$ & $\max 5$ & - & - & - & - & - \\
\hline
\end{tabular}

Table 2

Main mechanical and thermal properties of used materials

\begin{tabular}{llllll}
\hline $\begin{array}{l}\text { Mechanical } \\
\text { properties }\end{array}$ & $\begin{array}{l}\text { Hardness } \\
(\text { Brinell })\end{array}$ & $\begin{array}{l}\text { Yield stress } \\
(\mathrm{MPa})\end{array}$ & $\begin{array}{l}\text { Ultimate tensile strength } \\
(\mathrm{MPa})\end{array}$ & $\begin{array}{l}\text { Specific heat capacity } \\
\left(\mathrm{J} \mathrm{Kg}^{-1} \mathrm{~K}\right)\end{array}$ & $\begin{array}{l}\text { Thermal conductivity } \\
\left(\mathrm{W} \mathrm{m} \mathbf{K}^{-1} \mathrm{~K}\right)\end{array}$ \\
\hline $42 \mathrm{CrMo} 4$ & 241 & 485 & 814 & $470-560$ & $32-40$ \\
$\mathrm{C} 15$ & 116 & 340 & 405 & $\approx 480$ & $\approx 52$ \\
\hline
\end{tabular}
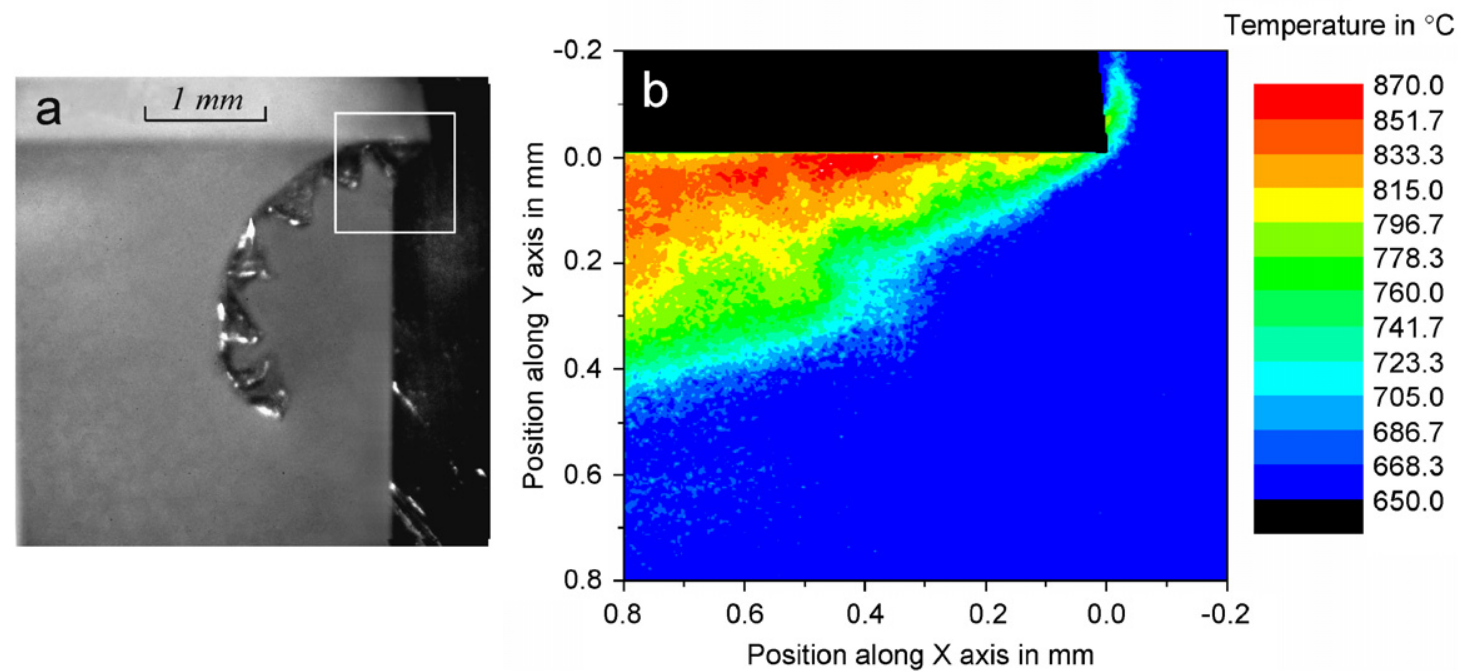

Fig. 7. Real time photograph (a) and temperature maps (b) obtained during orthogonal cutting test $\left(42 \mathrm{CrMo} 4, \alpha=0^{\circ}\right)$. (a) $t_{1}=0.30 \mathrm{~mm}, V_{\mathrm{C}}=16 \mathrm{~m} \mathrm{~s}^{-1}$ and (b) $t_{1}=0.26 \mathrm{~mm}, V_{\mathrm{C}}=22 \mathrm{~m} \mathrm{~s}^{-1}$.
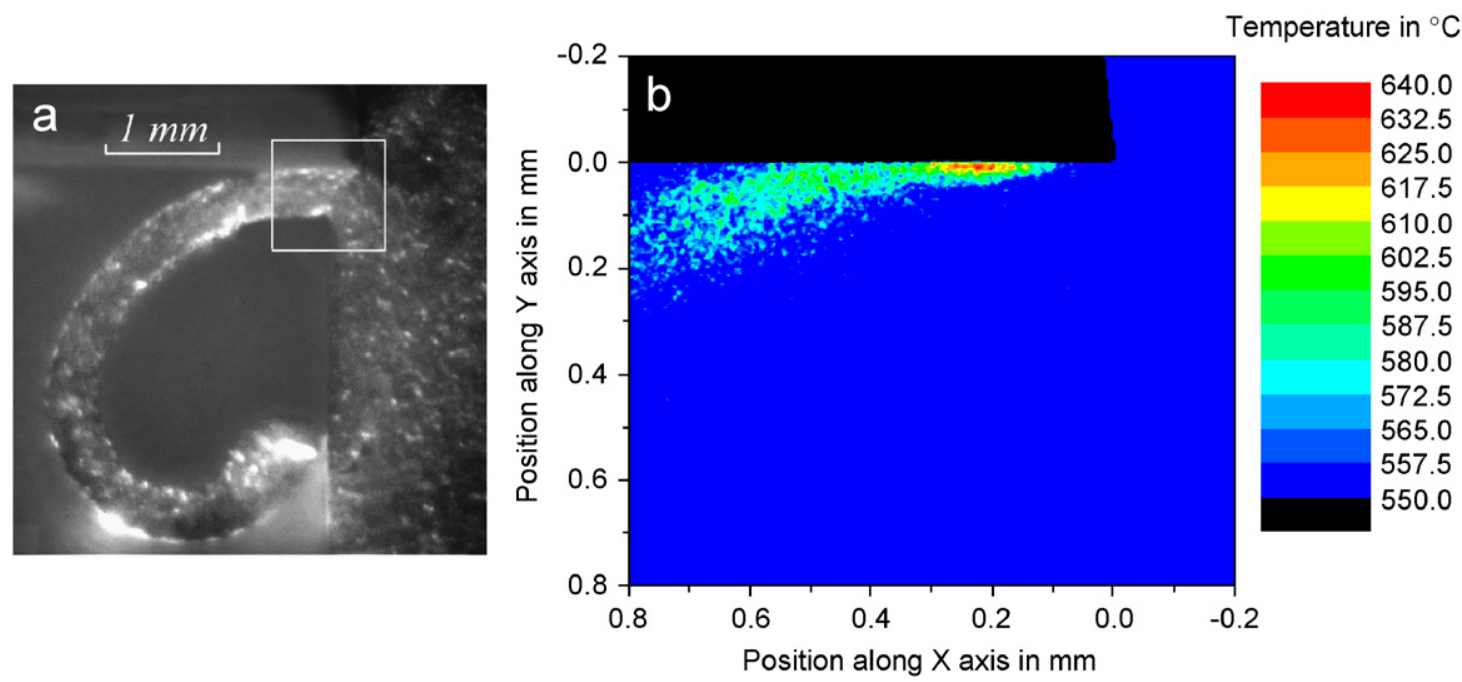

Fig. 8. Real time photograph (a) and temperature maps (b) obtained during orthogonal cutting test $\left(\mathrm{C} 15, \alpha=0^{\circ}\right)$. (a) $t_{1}=0.30 \mathrm{~mm}, V_{\mathrm{C}}=25 \mathrm{~m} \mathrm{~s}{ }^{-1}$ and (b) $t_{1}=0.26 \mathrm{~mm}, V_{\mathrm{C}}=23 \mathrm{~m} \mathrm{~s}^{-1}$. 
contact lengths are, respectively, $L_{\mathrm{C}}=0.62 \mathrm{~mm}(42 \mathrm{CrMo} 4$, $\left.t_{1}=0.30 \mathrm{~mm}\right)$ and $L_{\mathrm{C}}=0.66 \mathrm{~mm}\left(\mathrm{C} 15, t_{1}=0.30 \mathrm{~mm}\right)$. The tool-chip contact length $L_{\mathrm{C}}$ is an important factor that influences the cutting forces distribution applied on the tool and defines the thermal exchange zone with the tool.

It is also important to note that contrary to a stage of an industrial manufacturing, the experiments reproduced on the ballistic device presented here are of short durations in the order of hundred microseconds. Consequently, it is not possible to characterize heating in the tool because the time duration of conduction between the chip and the tool is very shortened.

The photographic recording the chip formation (Fig. 7a) realized with an exposure time of $1 \mu \mathrm{s}$, underlines the existence of several segments with a frequency range higher than the aperture time used during thermal recording $(64 \mu \mathrm{s})$. Consequently, to a large aperture time of $64 \mu \mathrm{s}$, applied for a cutting speed of $22 \mathrm{~m} / \mathrm{s}$, about three chip segments were generated for the $42 \mathrm{CrMo} 4$. The temperature map can be also considered as stationary only in a zone close to the tool-tip. This limitation does not concern the $\mathrm{C} 15$ steel for which the chip is continuous for all the speeds investigated here.

\subsection{Analysis of temperature fields in the chip}

Figs. $7 \mathrm{~b}$ and $8 \mathrm{~b}$ present thermal cartographies obtained for similar cutting speeds $(V \approx 22 \mathrm{~m} / \mathrm{s})$ and depths of cut $t_{1} \approx 0.30 \mathrm{~mm}$, for the two materials. On these pictures, a maximal temperature area is observed which is located near the tool-chip interface and, respectively, at a distance of the tool tip of $0.39 \mathrm{~mm}$ for $42 \mathrm{CD} 4$ steel and $0.22 \mathrm{~mm}$ for C15 steel. Globally the temperature fields measured in chips as well as maximal temperature are higher in the case of the $42 \mathrm{CrMo} 4$ steel. It must be notified that maximal temperature results from an average value measured on an area of $10 \mu \mathrm{m} \times 10 \mu \mathrm{m}$. Corresponding to temperature maps presented on Figs. 7 and 8, the maximal temperatures obtained are, respectively, $867{ }^{\circ} \mathrm{C}(42 \mathrm{CrMo} 4)$ and $630^{\circ} \mathrm{C}$ (C15).

For the 42CrMo4 steel, first results [20] obtained with a previous generation camera show similar temperature fields. However, it is necessary to note a low increase of absolute temperatures measured for identical cutting conditions. Indeed for a cutting speed $V=40 \mathrm{~m} / \mathrm{s}$ and a depth of cut $t_{1}=0.30 \mathrm{~mm}$, temperature measured along the tool-chip contact at a fixed distance $t_{1} / 2=0.15 \mathrm{~mm}$ was about $800^{\circ} \mathrm{C}$. At present, for a lower speed $(V=22 \mathrm{~m} / \mathrm{s})$ the temperature at the same point is $830^{\circ} \mathrm{C}$ for a similar depth of cut $t_{1}=0.26 \mathrm{~mm}$. This difference can be explained by a different emissivity factor due to the different surface of the workpiece according to the set of specimen. However, this difference of temperature remains lower than the margin error previously defined $\left(57^{\circ} \mathrm{C}\right)$.

On the thermographies $7 \mathrm{~b}$ and $8 \mathrm{~b}$, the highest temperatures are located near the tool-chip interface. To under- stand the temperature distribution in the chip, it is necessary to follow the different heat sources and heat transfers generated during the chip formation. As presented first in the introduction, the rise of temperature is initiated mainly in the primary shear zone and continued when the chip reach tool-chip interface. At the outflow of the primary zone, a simple estimation proposed for a building material (CRS1018) having mechanical and thermal characteristics close to $\mathrm{C} 15$ steel, defined the temperature $T_{0}=270{ }^{\circ} \mathrm{C}$ (for $V=250 \mathrm{~m} / \mathrm{min}$ or $4.1 \mathrm{~m} / \mathrm{s}$ ) [24]. For higher speeds $(23 \mathrm{~m} / \mathrm{s})$ this temperature $T_{0}$ seems to remain on the other hand less than $500{ }^{\circ} \mathrm{C}$ (corresponding to the threshold of detection for an aperture time of $400 \mu$ s and a gain of 255). Consequently, no heating is perceptible on the thermographies around the primary zone. The segmentation of the chip observed for $42 \mathrm{CrMo} 4$ steel, imposes shorter aperture times for the camera and so increases the threshold of detection to $600{ }^{\circ} \mathrm{C}$ (corresponding to an aperture time of $64 \mu$ s and a gain of 200). A higher yield stress of this material than the $\mathrm{C} 15$ leads to increase the temperature at the outflow of the primary zone. The most important gradient of temperature enables to note the primary shear orientation (cf. Fig. 7b).

It seems so that for $\mathrm{C} 15$ steel and even for $42 \mathrm{CrMo} 4$ steel, the maximal temperatures reached during the cut are located essentially in the secondary zone. Effects due to the friction combine with the shearing induce this maximal heating. Highest maximal temperatures are observed in the chip of $42 \mathrm{CrMo} 4$ steel with regard to C15 steel resulting from the increase of the friction coefficient (for $V=30 \mathrm{~m} / \mathrm{s}, \mu \approx 0.1$ (C15 [25]) and $\mu \approx 0.2$ (42CrMo4 [26]) and the increase of the yield stress (cf. Table 2).

Fig. 9 presents a thermal map of the chip at higher speed $V=61 \mathrm{~m} / \mathrm{s}$ for which the maximal temperature is $723^{\circ} \mathrm{C}$. In spite of a global increasing temperature in the chip following the increase of the speed, the maximal temperature is always along the rake face.

\subsection{Area of maximal temperature in the chip}

In the previous part, we saw that highest temperatures are located near the tool-chip interface. The maximum values of temperature focus on a small area which can be characterized by a point $\mathrm{P}$ situated close to the tool-chip interface and distant from the tool tip of a value $x_{1}$ (see Fig. 10). From this point, we draw in Fig. 11, the profiles of temperature according to a transversal (a) and longitudinal (b) direction. The decrease of temperature observed in Fig. 11a through the transverse profiles, points essentially to the conduction in the chip of the heat generated at the interface. One can note that very close to the interface, the slope of the temperature evolution increases with the cutting speed. As the heat flow entering in the chip is proportional to the gradient of temperature (Fourier's law), we deduce that heat entering the chip increases with the cutting speed. 

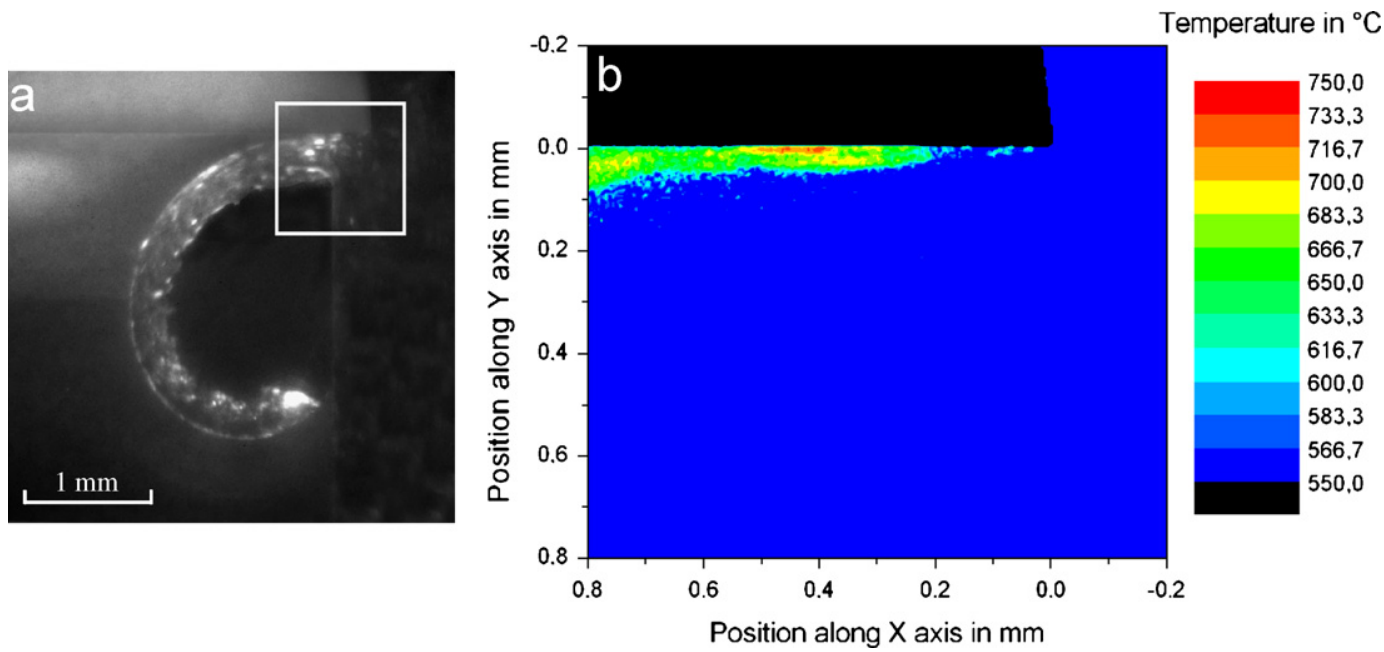

Fig. 9. Real time photograph (a) and temperature maps (b) obtained during orthogonal cutting test $\left(\mathrm{C} 15, \alpha=0^{\circ}\right)$. (a) $t_{1}=0.28 \mathrm{~mm}, V_{\mathrm{C}}=60 \mathrm{~m} \mathrm{~s}{ }^{-1}$ and (b) $t_{1}=0.38 \mathrm{~mm}, V_{\mathrm{C}}=61 \mathrm{~m} \mathrm{~s}^{-1}$.

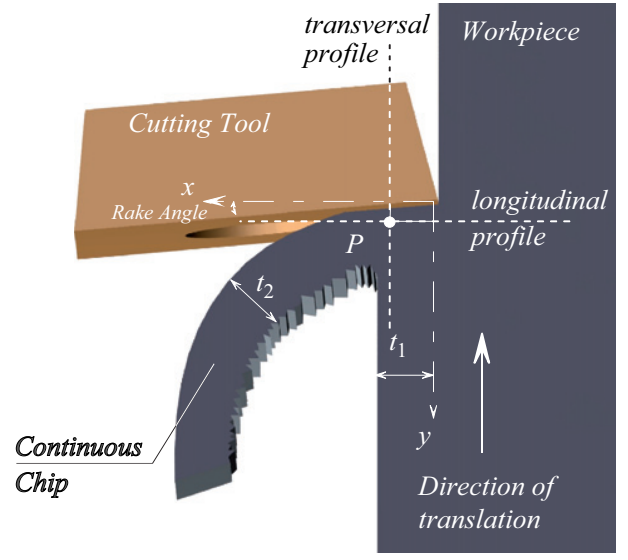

Fig. 10. Localization of maximal temperature area notified $\mathrm{P}$.

On Fig. 11b, whatever speed the temperature increases with the distance from the tool tip to reach a maximum. According to the tests presented Fig. 11 for $V=23$ and $61 \mathrm{~m} / \mathrm{s}$, the position of the maximal temperature is, respectively, of $x_{1}=0.22$ and $0.40 \mathrm{~mm}$. The longitudinal profile of temperature points essentially to the heat derived from the friction with the tool, initiated at the tool tip $(x=0)$ and reaching a maximal value for the distance $x_{1}$. The ratio $x_{1} / L_{\mathrm{C}}$ is dependent on the pressure distribution along the tool-chip interface. The hot spot position results from the combination of the normal stress decreasing with the distance from the tool tip and the increase time duration of the contact friction with the tool.

The cutting speed has a limited effect on the hot spot position normalized by the depth of cut (see Fig. 12). The mean value of $x_{1} / t_{1}$ is 0.8 ; however, we can observe a minimum value at about $40 \mathrm{~m} / \mathrm{s}$ which seems to correspond to the minimum cutting force already observed for this material [19].

\subsection{Evolution of the maximal temperature with the cutting speed - case of C15 steel machining}

In this part, the influence of the cutting speed on the maximum temperature reached in the chip is analyzed. The analytical approach will be established primarily on the machining of the $\mathrm{C} 15$ steel which ensures to get a continuous chip even at high cutting speed.

To model the temperature field in the chip, it is assume a convection of the matter at a constant speed $V_{\mathrm{C}}$ with a friction on the rake face over a length $L_{\mathrm{C}}$ (contact length) generating a heat source considered as uniform [11] (see Fig. 13). The chip speed $V_{\mathrm{C}}$ along the tool, can be expressed according to the cutting speed $V$ and by taking into account the experimental conditions $(\alpha=0)$ by the following relation:

$V_{\mathrm{C}}=V \tan \Phi$,

with $\Phi$ the angle of inclination of the primary shear zone (see Fig. 1) measured on the photographic recordings [23]. We suppose that the heat generated by friction per unit of area at the tool chip interface is written:

$Q=\mu(V) \frac{F_{\mathrm{N}} V_{\mathrm{C}}}{L_{\mathrm{C}} w}$.

$L_{\mathrm{C}}$ is the contact length which depends on the chip thickness. This value is measured on the photographic recordings of the chips [23]. $w$ is the chip width and $\mu$ is the dynamic friction coefficient between the tool and the chip. The value of $\mu$ is given from experimental data obtained on the same ballistic device [25]. $F_{\mathrm{N}}$ is the normal cutting force on the tool face. The intensity of this cutting force was measured during previous work under the same experimental conditions [20].

It is assumed that the heat generated by friction is constant along the surface of contact. At the tool chip interface under dry cutting conditions, the heat generated 

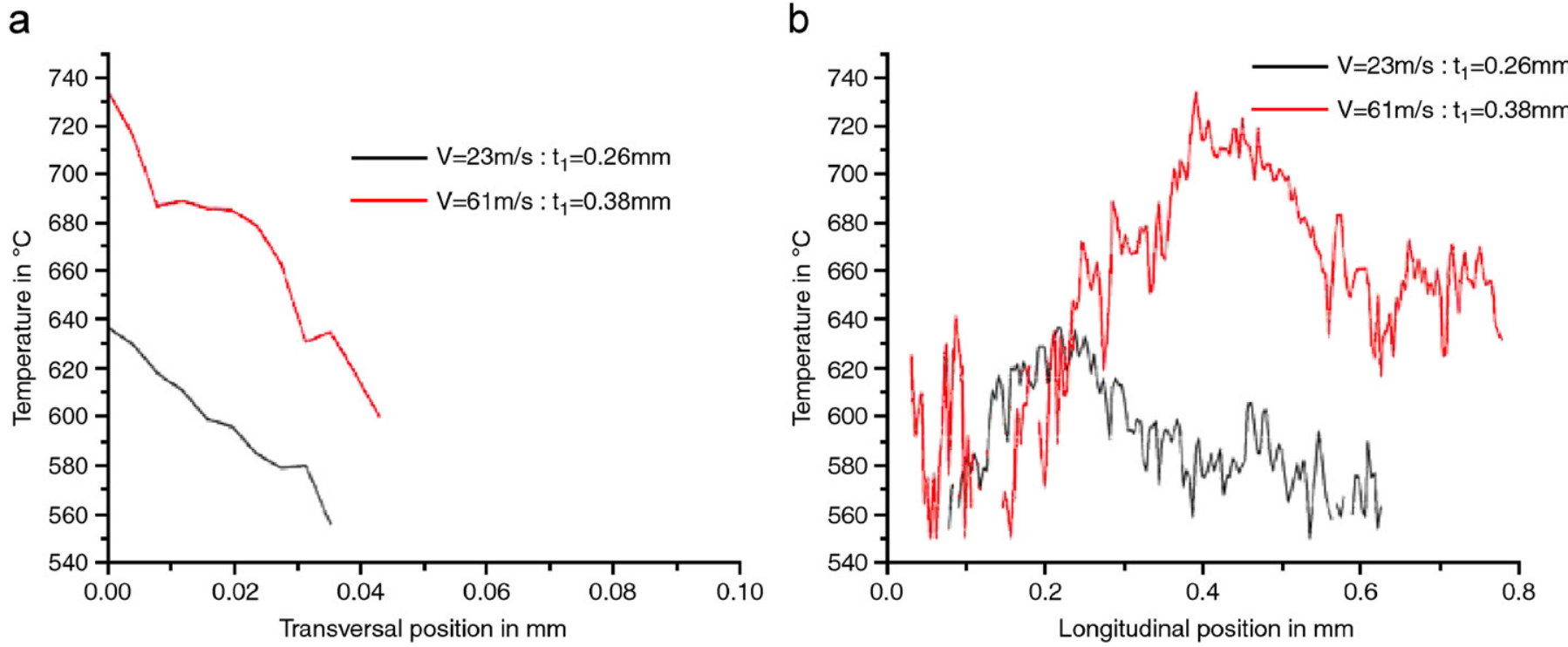

Fig. 11. Temperature profiles for $\mathrm{C} 15$ steel $\alpha=0^{\circ}, t_{1}=0.26 / 0.38 \mathrm{~mm}, V_{\mathrm{C}}=23 / 61 \mathrm{~ms}^{-1}, T_{\mathrm{MAX}}=630 / 720^{\circ} \mathrm{C}$ : (a) transversal profile and (b) longitudinal profile.

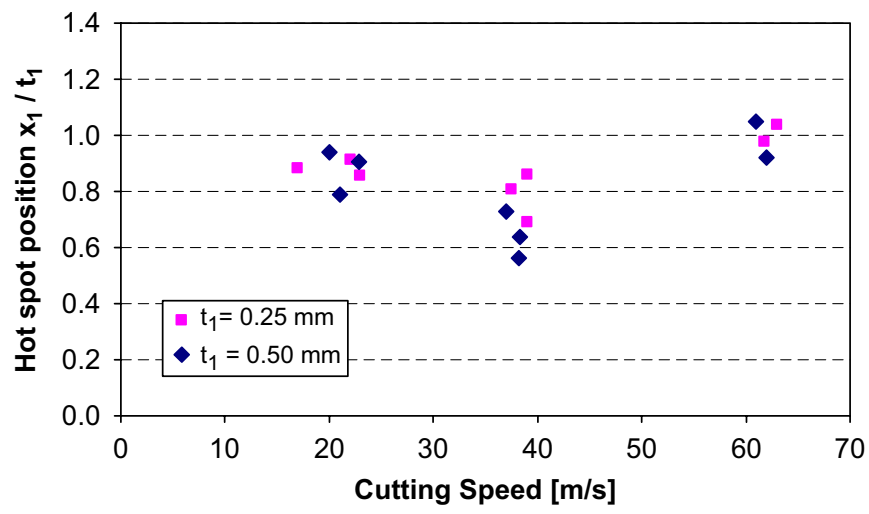

Fig. 12. Effect of the cutting speed on the maximum temperature location in the chip $\left(0.23 \mathrm{~mm} \leqslant t_{1} \leqslant 0.29 \mathrm{~mm}\right.$ and $0.48 \mathrm{~mm} \leqslant t_{1} \leqslant 0.52 \mathrm{~mm}, \alpha=0^{\circ}$, C15 steel).

by friction is divided in two terms:

$Q=Q_{\mathrm{C}}+Q_{\mathrm{t}}$,

where $Q_{\mathrm{C}}$ and $Q_{\mathrm{t}}$ are, respectively, the flows entering in the chip and in the tool. The proportion of heat entering in the chip, noted $\alpha_{\text {th }}$ is defined by [27]

$\alpha_{\mathrm{th}}=Q_{\mathrm{C}} / Q=b_{\mathrm{C}} /\left(b_{\mathrm{t}}+b_{\mathrm{C}}\right)$,

with, respectively, $b_{\mathrm{C}}=\sqrt{\rho_{\mathrm{C}} \lambda_{\mathrm{C}} C_{\mathrm{C}}}$ and $b_{\mathrm{t}}=\sqrt{\rho_{\mathrm{t}} \lambda_{\mathrm{t}} C_{\mathrm{t}}}$ the thermal effusivities of the chip and tool. $\rho_{\mathrm{C}}=$ $7800 \mathrm{~kg} \mathrm{~m}^{-3}, \quad \lambda_{\mathrm{C}}=52 \mathrm{~W} \mathrm{~m}^{-1} \mathrm{~K}^{-1}, \quad C_{\mathrm{C}}=480 \mathrm{~J} \mathrm{~kg}^{-1} \mathrm{~K}^{-1}$ and $\rho_{\mathrm{t}}=14900 \mathrm{~kg} \mathrm{~m}^{-3}, \quad \lambda_{\mathrm{t}}=61.2 \mathrm{~W} \mathrm{~m}^{-1} \mathrm{~K}^{-1}, \quad C_{\mathrm{t}}=$ $180.7 \mathrm{~J} \mathrm{~kg}^{-1} \mathrm{~K}^{-1}$ corresponding, respectively, to the density, the thermal conductivity and the heat capacity of the chip and the tool.

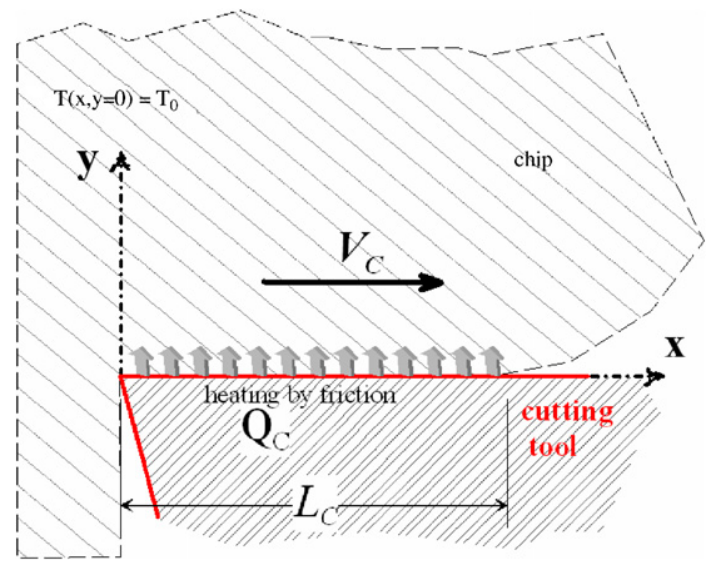

Fig. 13. Schematic view of the heat source applied to the chip used in the presented model.

With Eq. (3), we obtain the expression of the heat flow transmitted to the chip:

$Q_{\mathrm{C}}=\alpha_{\mathrm{th}} \mu\left(V_{\mathrm{C}}\right) \beta \frac{F_{\mathrm{N}} V_{\mathrm{C}}}{L_{\mathrm{C}} w}$.

The temperature field in the chip is then given by the following equations:

$a_{\mathrm{C}} \frac{\partial^{2} T}{\partial y^{2}}=V_{\mathrm{C}} \frac{\partial T}{\partial x}$ (heat equation),

$-\left.\lambda_{\mathrm{C}} \frac{\partial T}{\partial y}\right|_{y=0}=Q_{\mathrm{C}}$

and $T(x=0, y)=T_{0}$ (boundary conditions), 


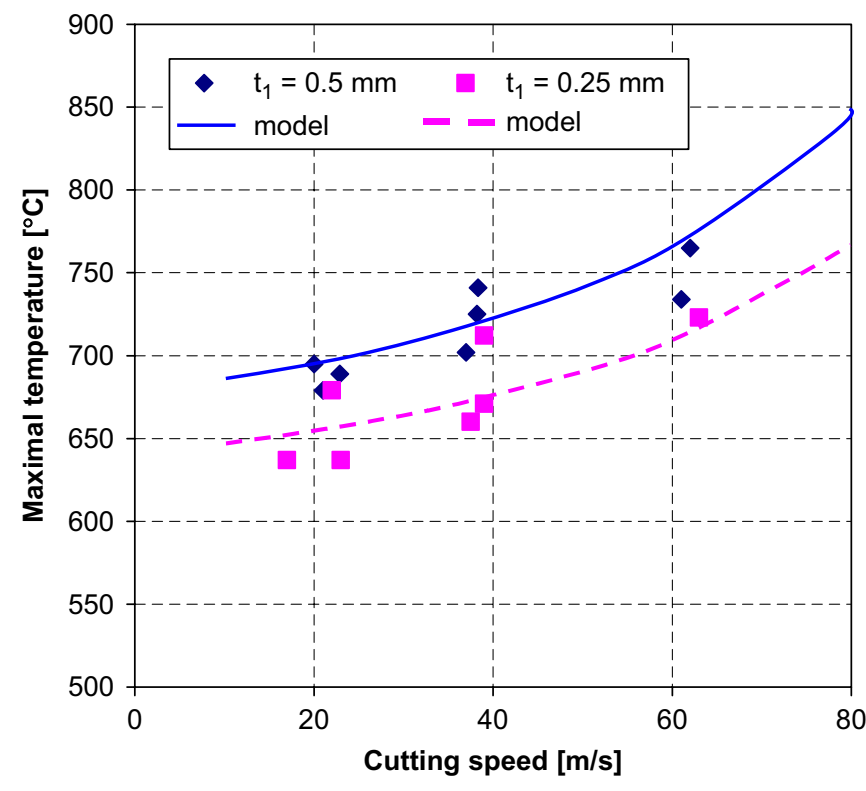

Fig. 14. Maximal temperature versus cutting speed for C15 steelexperimental results and analytical approach.

with $T_{0}$ temperature at exit of primary shear band and $a_{\mathrm{C}}$ the thermal diffusivity of the chip. The resolution of the heat equation with the Laplace transform gives the following result:

$$
\begin{aligned}
T(x, y)= & {\left.\left[2 \sqrt{\frac{a_{\mathrm{C}} x}{\pi V_{\mathrm{C}}}} \mathrm{e}^{-y^{2} V_{\mathrm{C}} / 4 a_{\mathrm{C}} x}-y \operatorname{erfc} \frac{y}{2 \sqrt{a_{\mathrm{C}} x / V_{\mathrm{C}}}}\right)\right] } \\
& \times \frac{Q_{\mathrm{C}}}{\lambda_{\mathrm{C}}}+T_{0} .
\end{aligned}
$$

The temperature increment $\Delta T$ is thus written:

$\Delta T(x, y)=T(x, y)-T_{0}$.

The maximum temperature is obtained for $x=L_{\mathrm{C}}$ and is written:

$T_{\max }=2 \frac{Q_{\mathrm{C}}}{\lambda_{\mathrm{C}}} \sqrt{\frac{a_{\mathrm{C}} L_{\mathrm{C}}}{\pi V_{\mathrm{C}}}}$.

One obtains by replacing the expression of $Q_{\mathrm{C}}$ :

$T_{\max }=2 \frac{\alpha_{\mathrm{th}} \mu(V) F_{\mathrm{N}}}{\lambda_{\mathrm{C}} w} \sqrt{\frac{a_{\mathrm{C}} V_{\mathrm{C}}}{\pi L_{\mathrm{C}}}}$.

Fig. 14 compares the results obtained by the model presented above and the experimental results. The maximum temperature measured in a C15 chip seems to follow an increasing evolution according to the cutting speed which is consistent with the model. For the speed range tested in this paper, the temperature does not seem to tend towards saturation point. Complementary tests to higher speeds should confirm the presence or not of a saturation of this maximum temperature with speed. The level of the maximum temperature follows the increase of the chip thickness.

\section{Conclusion}

A ballistic device allowing to realize cutting tests in orthogonal condition is equipped with a set-up of recording temperature fields in the chip. To increase the sensibility of the temperature measurement set-up, we use the pyrometry technique in the visible domain (short wavelength) reducing so the influence of the emissivity. Two steels, C15 and $42 \mathrm{CrMo} 4$ are tested for a range of cutting speeds from 15 to $65 \mathrm{~m} / \mathrm{s}$, exceeding the industrial speeds. Thermal cartographies recorded in chips underline the heterogeneity of the temperature fields and mainly the location of a maximal temperature area. The increase of the cutting speed raises globally temperature in the chip but seems to influence the location of the maximal temperature, which leads to be closer to the tool type for a critical speed of about $40 \mathrm{~m} / \mathrm{s}$. This critical cutting speed seems to correspond with the minimum of cutting forces [20]. The thermal recordings are completed with snapshot of the chip in formation. Important experimental data are then accessible, as the shear angle or the contact length at the tool-chip interface, which will complete previous results as the cutting forces or the friction coefficient. These experimental results allowed a simple model to be validated, characterizing maximal temperature reached in the chip for the $\mathrm{C} 15$ steel. For an increase of the speed from 10 to $65 \mathrm{~m} / \mathrm{s}$, maximal temperature in the chip increases continuously. The comparison of measurements and analytical results confirms the very good analytical predictions of cutting speed effects and the depth of cut on the estimated temperature.

\section{References}

[1] G. Barrow, A review of experimental and theoretical techniques for assessing cutting temperatures, Annals of the CIRP 22 (1973) 203-211.

[2] M.C. Shaw, Energy conversion in cutting and grinding, Annals of the CIRP 45 (1) (1996) 101-104.

[3] H. Ay, W.J. Yang, Heat transfer and life of metal cutting tools in turning, International Journal of Heat and Mass Transfer 41 (1998) 613-623.

[4] J. Rech, J.L. Battaglia, A. Moisan, Thermal influence of cutting tool coatings, Journal of Materials Processing Technology 159 (2005) 119-124.

[5] R. M'Saoubi, H. Chandrasekaran, Investigation of the effects of tool micro-geometry and coating on tool temperature during orthogonal turning of quenched and tempered steel, International Journal of Machine Tools and Manufacture 44 (2004) 213-224.

[6] J.C. Outerio, A.M. Dias, J.L. Lebrun, V.P. Astakhov, Machining residual stresses in AISI 316L steel and their correlation with the cutting parameters, Machining Science and Technology 6 (2) (2002) 251-270.

[7] R. Komanduri, Z.B. Hou, A review of the experimental techniques for the measurement of heat and temperature generated in some manufacturing processes and tribology, Tribology International 34 (2001) 653-682.

[8] M.B. Da Silva, J. Wallbank, Cutting temperature: prediction and measurement methods - a review, Journal of Materials Processing Technology 88 (1999) 195-202. 
[9] T.I. EL-Wardany, E. Mohamed, M.A. Elbestawi, Cutting temperature of ceramic tools in high speed machining of difficult-to-cut materials, International Journal of Machine Tools and Manufacture 36 (1996) 611-634.

[10] W. Grzesik, Experimental investigation of the cutting temperature when turning with coated indexable inserts, Journal of Machine Tools and Manufacture 39 (1999) 355-369.

[11] G. Boothroyd, Temperatures in orthogonal metal cutting, Proceedings of the Institution of Mechanical Engineers 177 (1963) 789-802.

[12] R.C. Dewes, E. Ng, K.S. Chua, P.G. Newton, D.K. Aspinwall, Temperature measurement when high speed machining hardened mould/die steel, Journal of Materials Processing Technology 92-93 (1999) 293-301.

[13] Y.K. Potdar, A.T. Zehnder, Measurements and simulations of temperature and deformation fields in transient metal cutting, Journal of Manufacturing Science and Engineering 125 (2003) 645-655.

[14] K.M. Vernaza-Pena, J.J. Mason, M. LI, Experimental study of the temperature field generated during orthogonal machining of an aluminum alloy, Experimental Mechanics 42 (2) (2001) 221-229.

[15] N.A. Abukhshim, P.T. Mativenga, M.A. Sheikh, Heat generation and temperature prediction in metal cutting: a review and implications for high speed machining, International Journal of Machine Tools and Manufacture 46 (2006) 782-800.

[16] N. Ranc, V. Pina, G. Sutter, S. Philippon, Temperature measurement by visible pyrometry - orthogonal cutting application, Journal of Heat transfer ASME 126 (2004) 931-936.

[17] D. O'Sullivan, M. Cotterell, Temperature measurement in single turning point, Journal of Materials Processing Technology 118 (2001) 301-308

[18] B. Muller, Temperature measurements with a fibre-optic two-colour pyrometer, in: H. Schulz (Ed.), Scientific Fundamentals of High
Speed Cutting, Carl Hanser Verlag, München, Wien, 2001, pp. 181-186.

[19] G. Sutter, L. Faure, A. Molinari, N. Ranc, V. Pina, An experimental technique for the measurement of temperature fields for the orthogonal cutting in high speed, International Journal of Machine Tools and Manufacture 43 (2003) 671-678.

[20] G. Sutter, A. Molinari, L. Faure, J.R. Klepaczko, D. Dudzinski, An experimental study of high speed orthogonal cutting, Transactions of the ASME, Journal of Manufacturing Science and Engineering 12 (1998) 169-172.

[21] N. Ranc, V. Pina, P. Hervé, Optical measurements of phase transition and temperature in adiabatic shear bands in titanium alloys, Journal de Physique IV France 10 (Pr9) (2000) 347-352.

[22] Y.S. Touloukian, D.P. DeWitt, Thermophysical properties of matter - thermal radiative properties, Metallic elements and alloys, vol. 7, IFI/Plenum, New York, Washington, 1970.

[23] G. Sutter, Chip geometries during high speed machining for orthogonal cutting conditions, International Journal of Machine Tools and Manufacture 45 (2005) 719-726.

[24] D. Dudzinski, A. Molinari, A modelling of cutting for viscoplastic materials, International Journal of Mechanical Sciences 4 (1997) 369-389.

[25] G. Sutter, S. Philippon, A. Molinari, An experimental investigation of dry friction for a large range of sliding velocities, Matériaux et Techniques, Hors Série (2004) 33-37.

[26] G. Sutter, A. Molinari, Analysis of the cutting force components and friction in high speed machining, ASME Journal of Manufacturing Science and Engineering 127 (2005) 245-250.

[27] E.-G. Ng, D.K. Aspinwall, D. Brazil, J. Monaghan, Modelling of temperature and forces when orthogonally machining hardened steel, International Journal of Machine Tools and Manufacture 39 (1999) 885-903. 